\title{
A Novel Silica-Nylon Mesh Reinforcement for Dental Prostheses
}

\author{
Tarcisio José de Arruda Paes-Junior, ${ }^{1}$ Humberto Lago de Castro, ${ }^{2}$ \\ Alexandre Luiz Souto Borges, ${ }^{1}$ Alvaro Della Bona, ${ }^{3}$ \\ and Fernanda de Cássia Papaiz Gonçalves ${ }^{4}$ \\ ${ }^{1}$ Department of Dental Materials and Prosthodontics, Institute of Science and Technology, São Paulo State University (Unesp), \\ São José dos Campos, SP, Brazil \\ ${ }^{2}$ Postgraduation Program in Prosthodontics, Department of Dental Materials and Prosthodontics, Institute of Science and Technology, \\ São Paulo State University (Unesp), São José dos Campos, SP, Brazil \\ ${ }^{3}$ Postgraduation Program in Dentistry, Dental School, University of Passo Fundo, Passo Fundo, RS, Brazil \\ ${ }^{4}$ Postdoctoral Program, Institute of Aeronautics Technology (ITA), São José dos Campos, SP, Brazil
}

Correspondence should be addressed to Tarcisio José de Arruda Paes-Junior; tarcisio@fosjc.unesp.br

Received 9 June 2017; Revised 25 August 2017; Accepted 12 September 2017; Published 16 October 2017

Academic Editor: Jun Liu

Copyright (C) 2017 Tarcisio José de Arruda Paes-Junior et al. This is an open access article distributed under the Creative Commons Attribution License, which permits unrestricted use, distribution, and reproduction in any medium, provided the original work is properly cited.

\begin{abstract}
Statement of the Problem. Acrylic resin-based dentures can fracture; thus they can benefit from reinforcement. Purpose. To evaluate the effect of a novel reinforcement structure made of nylon fibers and silica particles on the flexural strength of acrylic resin after relining and aging. Materials and Methods. Bar-shaped specimens were fabricated and divided into the following experimental groups $(n=20)$ : control (acrylic resin without reinforcement); acrylic resin nylon fiber-reinforced; acrylic nylon and silica fiberreinforced; acrylic nylon fiber-reinforced-relined; acrylic nylon and silica fiber-reinforced-relined. Half of the specimens from each group were aged by thermomechanical cycling $\left(10000\right.$ cycles between $5^{\circ} \mathrm{C}$ and $\left.55^{\circ} \mathrm{C}\right)$ before flexural strength testing to failure using a universal testing machine. Data (MPa) were statistically analyzed using analysis of variance and Tukey tests $(\alpha=5 \%)$. Results. Adding nylon fibers or silica-containing nylon fibers significantly increased the flexural strength of all the groups tested. Within the similar groups processed in the same manner, the relining procedure reduced the flexural strength of the specimens, whereas aging process had no effect on the strength values. Conclusion. Incorporating a silica-containing nylon fiber mesh into acrylic resin yielded the greatest flexural strength for the evaluated structures.
\end{abstract}

\section{Introduction}

Despite the technological advances and improvements made in oral health, a large percentage of the population are edentulous. In such cases, the use of complete dentures remains a viable treatment [1]. Complete dentures are fabricated using acrylic resin that provides dimensional stability, strength, and hardness, resulting in comfortable, esthetically pleasing, and highly functional dentures [2].

Poly(methyl methacrylate) (PMMA) exhibits good biomechanical characteristics and can be processed using dry heat, steam, chemical activation, visible light, and microwave energy [2-5]. Because of a considerable incidence of denture fracture, the need for repair has promoted the development of new materials and techniques improving fracture resistance and flexural strength of dentures. Some attempts have been made to incorporate metal structures and polymers (polyethylene and nylon) or glass fibers into the acrylic resin [6-8].

Nylon fibers are polyamides that have fewer than $85 \%$ of their amide groups attached to aromatic rings. The polar amide groups allow adjacent chains to form hydrogen bonds with each other, greatly improving the crystallinity, strength, and durability. They can be easily dyed and embossed [9].

The effectiveness of fiber reinforcement depends on its structure design, orientation with respect to the applied force, total volume fraction, and bonding to resin matrix $[6,8,10]$. In addition, adequate load transfer between resin 
matrix and fibers is essential $[8,11]$. Poorly impregnated fibers increase water absorption, which has a negative effect on the mechanical properties of the resin. The greater the number of siloxane bridges, the lower the amount of water absorbed, resulting in greater adhesion between matrix and fibers [8].

Another condition used to evaluate the materials properties is the aging process. Thermal cycling is an in vitro method performed to partially evaluate degradation of the material tested, aiming to simulate oral conditions. Materials as polyethylene fibers have been effectively used to reinforce acrylic resins, especially the ones activated by visible light. But, similar success was not observed for thermally activated resins, mainly after aging [12]. Nevertheless, a shorter thermal aging protocol did not influence the fracture load of fiberreinforced bisacrylic interim partial fixed dental prosthesis [8].

Glass fiber reinforcement improved the flexural strength of acrylic resin under aging process [13]. The incorporation of great amounts of silica particles in thermally activated acrylic resin can increase its flexural strength, hardness, and brittleness. Similar situation occurred when silica was added to nylon fibers and used as reinforcement to dental prostheses in bisacrylic resin [8].

The authors have proposed to test a new method of acrylic resin reinforcement; then the aim of this study was to evaluate the effect of nylon fiber and silica mesh on the flexural strength of acrylic resin after relining and aging, testing the following hypotheses:

(1) Nylon fiber added or not by silica improves the flexural strength of acrylic resin.

(2) Relining decreases the flexural strength of evaluated structures.

(3) Aging, by thermomechanical cycling, decreases the flexural strength of evaluated structures.

\section{Materials and Methods}

2.1. Nylon Mesh Fiber. A 6.0 nylon mesh structure (mesh: $0.6 \mathrm{~mm}$ thick fiber with $3 \mathrm{~mm}$ spacing) and an identical fiber mesh containing silica particles were fabricated (Natmar Moldes e Plasticos Ltd.). For the latter, silica particles were added to the nylon mass before injection press to shape, allowing for uniform distribution of silica throughout the nylon fiber-based mesh (UNESP Patent no. BR20120281198) (Figure 1(e)).

Experimental groups are listed in Experimental Groups and Abbreviations.

Firstly, specimens used for the control and aged groups $(n=10)$ were made; therefore stainless steel bars $(25 \mathrm{~mm} \times$ $10.5 \mathrm{~mm} \times 3.3 \mathrm{~mm}$ ) were fabricated and used as matrixes. They were included in plastic flasks for microwave polymerization (GST-Vipi, Dental Vipi Ltda., Pirassununga, Brazil) using a type-II plaster (Herodent, Vigodent S/A, Rio de Janeiro, Brazil) and dental silicone (VipiSil, Vipi Dental Inc., Pirassununga, Brazil.). The molds were filled with acrylic resin thermally activated by microwave energy (\#12964, Vipi Wave, Dental Vipi Ltda., Pirassununga, Brazil) that was manipulated and polymerized according to manufacturer's instructions in a microwave oven. Flask was opened; specimens were removed and stored in $37^{\circ} \mathrm{C}$ water.

Specimens for the remaining experimental groups $(n=$ 10) were fabricated following similar procedure. The nylon fiber and the silica-containing nylon fiber were incorporated into the acrylic resin making, respectively, and their corresponding aged groups (see Experimental Groups and Abbreviations).

To prepare such specimens, a layer of acrylic resin was placed into the molds and a stainless steel bar $(25 \mathrm{~mm} \times$ $10.5 \mathrm{~mm} \times 1.5 \mathrm{~mm}$ ) was placed on it. The flask was closed and pressure was applied to create the space for the next layer. Flask was opened, metal bar was removed, and the nylon fiber mesh or the silica-containing nylon fiber mesh was accommodated on the acrylic resin. Another layer of acrylic resin was applied on the mesh and flask was closed.

Similar strategy was used to begin the fabrication of the relined specimens. Thus, acrylic resin bar-shaped samples $(25 \mathrm{~mm} \times 10.5 \mathrm{~mm} \times 1.5 \mathrm{~mm})$ were fabricated, as described above, and the nylon fiber mesh was accommodated on the acrylic resin for the specimens, or the silica-containing nylon fiber mesh was accommodated on the acrylic resin for the specimens. All samples were placed in a silicon mold and two coats of primer (Tokuso Rebase, Tokuyama Dental Corporation, Tokyo, Japan) were applied on top surface of samples using a disposable brush. The reliner resin (Tokuyama Rebase II Fast, Tokuyama Dental Corporation, Tokyo, Japan) was prepared according to manufacturer's instructions and applied on the primed surface of samples to fill the mold $(25 \mathrm{~mm} \times 10.5 \mathrm{~mm} \times 3.3 \mathrm{~mm})$. A glass plate was placed on the top of the mold, digital pressure was applied, and excess material was removed. The polymerized specimens were immersed for $3 \mathrm{~min}$ in $200 \mathrm{~mL}$ of hardener solution prepared as manufacturer's recommendation (Tokuso Resin Hardener, Tokuyama Dental Corporation, Tokyo, Japan); then specimens were washed in running water. Acrylic resin surfaces were polished to aqueous $1 \mu \mathrm{m}$ alumina suspension on polishing cloths.

All specimens were placed in $37^{\circ} \mathrm{C}$ distilled water for $48 \mathrm{~h}$ before aging or testing. The aging protocol consisted of thermomechanical cycling (Erios ER-11000, Erios, São Paulo, Brazil) where specimens were subjected to 10,000 cycles at $3.8 \mathrm{~Hz}$ under a pressure of $25 \mathrm{bar}$, with temperature changing between 5 and $55^{\circ} \mathrm{C}$ with $15 \mathrm{~s}$ dwell time.

Semiquantitative and qualitative analyses of the nylon fiber mesh and silica-containing nylon fiber mesh were performed using scanning electron microscopy (SEM) and energy dispersive X-ray (EDX). Mesh structures were mounted on aluminum stubs using carbon-coating paste and carbon coated in a vacuum evaporation system (Ion Equipment Co., Santa Clara, CA, USA). The thickness of the carbon layer was approximately $250 \AA$. Secondary electron and backscattered images (SEI and BSI) were recorded. The overall composition of the mesh was determined by EDX (detector model 6070, LEO Electron Microscopy, UK) using a scanning electron microscope (JSM-T330A, Jeol Ltd., Tokyo, Japan). The analyses were performed at an accelerating voltage of $15 \mathrm{kV}$. Compositional analyses were performed five 


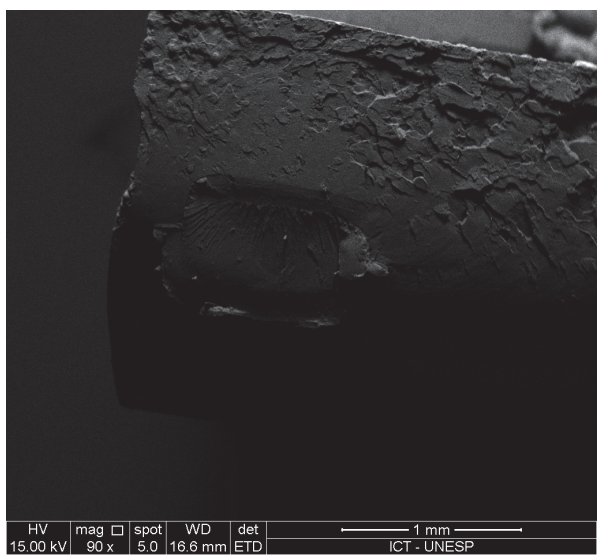

(a) Representative SEM images of acrylic resin sample added to silica-containing nylon mesh $(\times 90)$

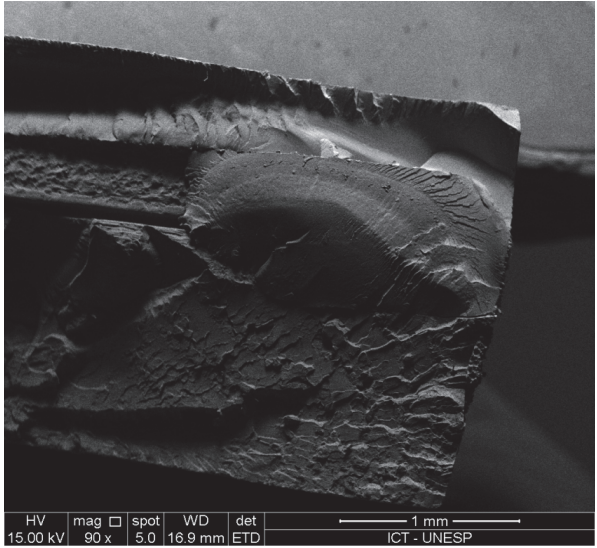

(b) Representative SEM images of acrylic resin and relining material sample added to silica-containing nylon mesh $(\times 90)$

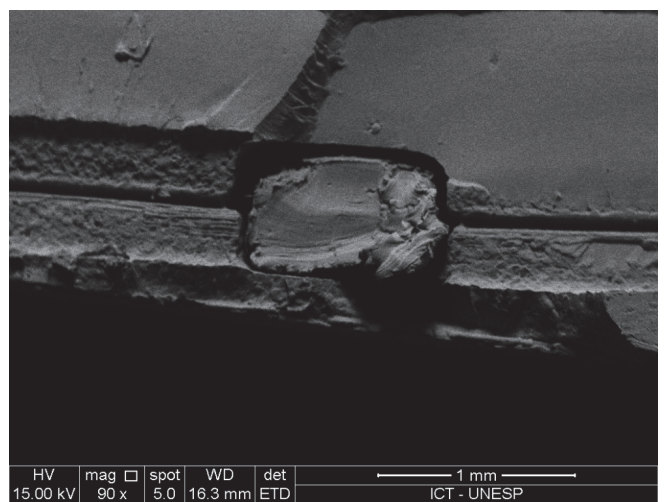

(c) Representative SEM images of acrylic resin sample added to nylon mesh without silica $(\times 90)$

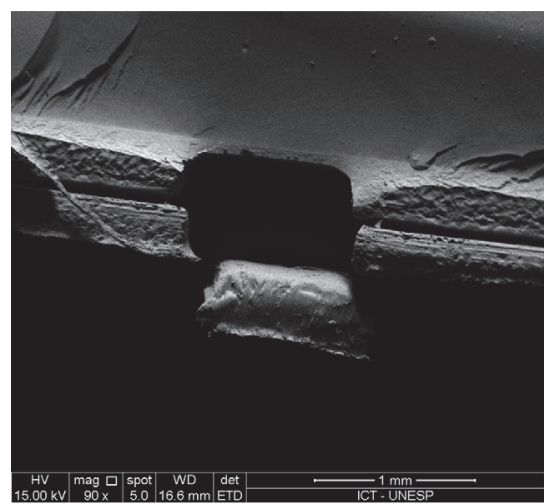

(d) Representative SEM images of acrylic resin and relining material sample added to nylon mesh without silica $(\times 90)$

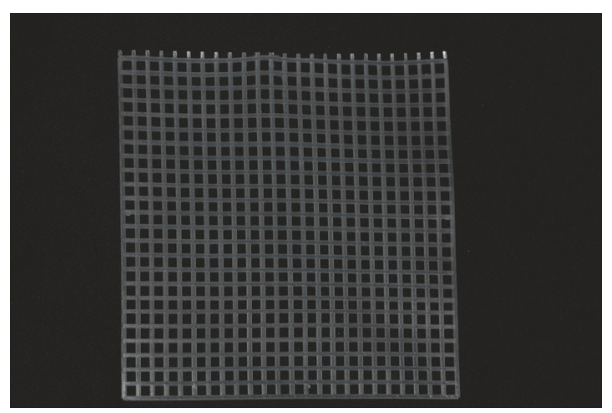

(e) Example of nylon mesh

Figure 1

times in different locations and average values of composition were determined. Compositional element and compound concentrations above $1 \mathrm{wt} \%$ were recorded.

Specimens were subjected to the three-point bending test using a universal testing machine (DL-1000, EMIC Equipment and Systems Ltd., São José dos Pinhais, PR, Brazil) with a cross-head speed of $1 \mathrm{~mm} / \mathrm{min}$ (ISO 20795-1:2013). Flexural strength values (in $\mathrm{MPa}$ ) were statistically analyzed using three-way analysis of variance (ANOVA) and the Tukey test (Statistix 8.0) considering three factors (reinforcement, relining, and aging) and a significant level ( $\alpha=5 \%)$.

\section{Results}

Compositional analysis of the silica-containing nylon fiber mesh (Table 1) confirmed the presence of $\mathrm{SiO}_{2}$ (10.5 wt\% on average). SEM images of reinforced samples were shown (Figures 1(a), 1(b), 1(c), and 1(d)).

Statistical analysis showed factor interactions and statistical significant differences between groups $(p<0.05)$ (Table 2).

When evaluating the aging effect on similar groups (aged and not aged), the aging protocol used in this study did 
TABLE 1: Spectrum acquisition by EDX.

\begin{tabular}{|c|c|c|c|c|c|c|}
\hline Element & $\begin{array}{c}\text { Unn. } \\
\text { [wt.\%] }\end{array}$ & $\begin{array}{c}\text { C norm. } \\
\text { [wt. \%] }\end{array}$ & $\begin{array}{c}\text { C Atom. } \\
\text { [wt.\%] }\end{array}$ & Compound norm. & $\begin{array}{l}\text { Comp. } \\
\text { [wt.\%] }\end{array}$ & $\begin{array}{c}C \text { error (3 Sigma) } \\
\text { [wt. } \%]\end{array}$ \\
\hline Carbon & 0.00 & 0.00 & 0.00 & & 0.00 & 0.00 \\
\hline Oxygen & 0.70 & 8.17 & 32.27 & & 0.00 & 0.64 \\
\hline Aluminium & 0.25 & 2.88 & 6.75 & $\mathrm{Al}_{2} \mathrm{O}_{3}$ & 5.45 & 0.22 \\
\hline Palladium & 7.16 & 84.03 & 49.90 & & 84.03 & 1.32 \\
\hline Silicon & 0.42 & 4.92 & 11.07 & $\mathrm{SiO}_{2}$ & 10.53 & 0.26 \\
\hline Total & 8.52 & 100.00 & 100.00 & & & \\
\hline
\end{tabular}

TABLE 2: Mean and standard deviation (SD) values (in MPa) of flexural strength followed by the statistical grouping $(*)$ for all experimental groups.

\begin{tabular}{lr}
\hline Groups & Mean $^{2} \mathrm{SD}^{*}$ \\
\hline aR: aged relined acrylic resin & $51.5 \pm 4.1^{\mathrm{A}}$ \\
R: relined acrylic resin & $54.6 \pm 3.0^{\mathrm{A}}$ \\
aRN: aged relined nylon fiber-reinforced acrylic resin & $70.1 \pm 4.2^{\mathrm{B}}$ \\
C: acrylic resin & $75.4 \pm 3.1^{\mathrm{B}}$ \\
aC: aged acrylic resin & $75.9 \pm 5.8^{\mathrm{B}}$ \\
RN: relined nylon fiber-reinforced acrylic resin & $79.9 \pm 1.6^{\mathrm{B}}$ \\
aN: aged nylon fiber-reinforced acrylic resin & $96.0 \pm 16.1^{\mathrm{C}}$ \\
aRSN: aged relined silica-containing nylon fiber-reinforced acrylic resin & $101.3 \pm 3.1^{\mathrm{C}}$ \\
RSN: relined silica-containing nylon fiber-reinforced acrylic resin & $105.6 \pm 6.1^{\mathrm{C}}$ \\
N: nylon fiber-reinforced acrylic resin & $109.0 \pm 10.9^{\mathrm{C}}$ \\
aSN: aged silica-containing nylon fiber-reinforced acrylic resin & $150.1 \pm 13.1^{\mathrm{D}}$ \\
SN: silica-containing nylon fiber-reinforced acrylic resin & $152.5 \pm 14.8^{\mathrm{D}}$ \\
\hline
\end{tabular}

${ }^{*}$ Values followed by different letters are statistically different $(p<0.05)$.

not influence flexural strengths $(p>0.05)$. Using the same rationale for relining, comparing similar structures (relined and not relined), relining negatively influenced the mean flexural strength values of the evaluated structures $(p<0.05)$. Reinforcing acrylic resin structures by adding nylon fibers or silica-containing nylon fibers significantly increased the flexural strength.

\section{Discussion}

Complete dentures are usually made out of acrylic resin, because it is easily processed, relatively inexpensive, and well accepted by oral tissues. Nevertheless, it exhibits few structural limitations, including relatively low fracture toughness, with the PMMA-based polymer showing a high incidence of fractures [14]. The failures may be due to insufficient material thicknesses, inadequate processing (usually poor polymerization), low flexural strength, changes in the occlusal relationship, the use of inadequate material for cleaning and polishing the dentures, and damage resulting from dropping the prosthesis. These reasons have driven the development of materials and techniques to improve the flexural strength and toughness of acrylic resins. Therefore, the present study aimed to reinforce acrylic resin using nylon fiber or silicacontaining nylon fiber meshes. Capacity to increase strength, type, and orientation of the fiber, adhesion to polymer matrix, and the amount of fiber and silica adding to the acrylic resin structure are some aspects that direct the indication of reinforcement materials $[10,11]$. Thus, this study used a novel silica-containing nylon fiber mesh based on previously evaluations [8] and structural improvements (UNESP Patent no. BR20120281198).

The results showed a mean flexural strength value of $75 \mathrm{MPa}$ for acrylic resin (control group), which is compatible with the minimum recommended value $(65 \mathrm{MPa})$ of ISO standard 20795-1:2013 [15]. Whenever a reinforcement structure (nylon fiber mesh or silica-containing nylon fiber mesh) was incorporated into the acrylic resin, the flexural strength significantly increased, confirming the first and second hypotheses, and is in agreement with previous studies [11, 16, 17].

Fiber reinforcement is only successful if the load is transferred from matrix to fibers [11]. The silanized silica particles incorporated in the nylon fiber probably enhanced the adhesion between the nylon fiber mesh and the resin, which improved the load transfer and stress distribution throughout the structure. In some cases, the greater the number of siloxane bridges, the lower the amount of water absorbed, resulting in greater adhesion between the matrix and fibers [11]. On the contrary, poorly impregnated fibers increase water absorption, which negatively affects the mechanical properties of the structure. In addition, voids caused by poor resin-to-fiber impregnation accumulate oxygen that inhibits the polymerization process, reduce the bending resistance, 
and increase the residual monomer content, leading to reactions that irritate the oral mucosa [11]. The fiber mesh used in the present study formed a continuous reinforcement, facilitating uniform stress distribution under loading, which probably improves mechanical properties. A study using glass fiber research was previously reported [17] and showed greater flexural strengths when using unidirectional glass fibers in the polymer array than using braided fibers. However, a study [18] reported no significant improvement on flexural strength from glass fiber reinforcement, which should be incorporated in amounts not greater than $20 \mathrm{wt} \%$ into acrylic resin.

The present study also showed that relining significantly decreased the flexural strengths of the evaluated structures $(p<0.05)$, confirming the third study hypothesis. Such results were mostly expected because of specimen fabrication that essentially simulates clinical relining but inevitably reduces the structural resistance of the original specimen. Nevertheless, using any of the evaluated reinforcing meshes significantly increases the flexural strength of relined structures, which suggests an adequate bond between the relined and the fiber mesh. Important to note is that the relined silicacontaining nylon fiber-reinforced acrylic resin (group RSN) showed similar flexural strength to the nylon fiber-reinforced acrylic resin (group N). SEM images showed the nylon mesh containing silica-maintained bonding with acrylic resin or relining material (Figures 1(a) and 1(b)); on the other hand, nylon mesh without silica showed separation of resin-based materials (Figures $1(\mathrm{c})$ and $1(\mathrm{~d})$ ).

Adequate oral service simulation for laboratory evaluations is a great challenge [19]. The present study used thermomechanical cycling as an aging procedure to evaluate the combining effect of water, temperature, and low loads on the flexural strength of all experimental structures. Data showed that the aging protocol used in this study did not influence flexural strengths $(p>0.05)$, rejecting the fourth hypothesis. Reports are controversial regarding the effect of aging on acrylic resin-based structures, mostly because the diverse aging protocols used in published papers [20-22] make any comparison with the results of the present study impossible. Aging standardization to simulate oral service is mostly necessary.

To sum up, the present study evaluates a novel reinforcing fiber mesh for acrylic resin showing promising results when added to acrylic resin, relined or not, even after aging. Further studies are encouraged to evaluate this novel reinforcing mesh with harder clinical challenges and longer aging protocols, aiming to improve the quality and longevity of dental prostheses.

\section{Conclusions}

Within the limitations of the study, it is possible to conclude the following:

(1) Incorporating a silica-containing nylon fiber mesh to acrylic resin showed the greatest flexural strength for the evaluated structures.

(2) Relining acrylic resin reduced the flexural strength.
(3) The aging protocol using thermomechanical cycling did not significantly affect the evaluated structures.

\section{Experimental Groups and Abbreviations}

Groups ( $n=10)$

aR: $\quad$ Aged relined acrylic resin

$\mathrm{R}: \quad$ Relined acrylic resin

aRN: Aged relined nylon fiber-reinforced acrylic resin

C: $\quad$ Acrylic resin

aC: $\quad$ Aged acrylic resin

$\mathrm{RN}$ : Relined nylon fiber-reinforced acrylic resin

aN: Aged nylon fiber-reinforced acrylic resin

aRSN: Aged relined silica-containing nylon fiber-reinforced acrylic resin

RSN: Relined silica-containing nylon fiber-reinforced acrylic resin

$\mathrm{N}$ : Nylon fiber-reinforced acrylic resin

aSN: Aged silica-containing nylon fiber-reinforced acrylic resin

SN: Silica-containing nylon fiber-reinforced acrylic resin.

\section{Additional Points}

Clinical Implications. Complete dentures fabricated using acrylic resin have a high incidence of fracture; the reinforcement of the denture base resin might improve the mechanical properties of the resin and consequently longevity of prosthesis.

\section{Conflicts of Interest}

The authors declare that they have no conflicts of interest.

\section{Acknowledgments}

This paper is supported by São Paulo Research Foundation (FAPESP) (Grant no. 2011/07334-6).

\section{References}

[1] D. A. Felton, "Edentulism and comorbid factors," Journal of Prosthodontics, vol. 18, no. 2, pp. 88-96, 2009.

[2] V. P. Reitz, J. L. Sanders, and B. Levin, "The curing of denture acrylic resins by microwave energy-physical properties," Quintessence International, vol. 16, pp. 547-551, 1985.

[3] J. P. De Clerck, "Microwave polymerization of acrylic resins used in dental prostheses," The Journal of Prosthetic Dentistry, vol. 57, no. 5, pp. 650-658, 1987.

[4] B. Levin, J. L. Sanders, and P. V. Reitz, "The use of microwave energy for processing acrylic resins," The Journal of Prosthetic Dentistry, vol. 61, no. 3, pp. 381-383, 1989.

[5] S. R. Shlosberg, C. J. Goodacre, C. A. Munoz, B. K. Moore, and R. J. Shnell, "Microwave energy polymerization of poly (methyl methacrylate) denture base resin," The International Journal of Prosthodontics, vol. 2, pp. 453-458, 1989. 
[6] P. K. Vallittu, "Comparison of two different silane compounds used for improving adhesion between fibres and acrylic denture base material.," Journal of Oral Rehabilitation, vol. 20, no. 5, pp. 533-539, 1993.

[7] O. M. Doğan, G. Bolayir, S. Keskin, A. Doğan, B. Bek, and A. Boztuğ, "The effect of esthetic fibers on impact resistance of a conventional heat-cured denture base resin," Dental Materials, vol. 26, no. 2, pp. 232-239, 2007.

[8] C. S. Almeida, M. Amaral, F. De Cássia Papaiz Gonçalves, and T. J. De Arruda Paes, "Effect of an experimental silica-nylon reinforcement on the fracture load and flexural strength of bisacrylic interim partial fixed dental prostheses," Journal of Prosthetic Dentistry, vol. 115, no. 3, pp. 301-305, 2016.

[9] K. J. Anusavice, Phillips Science of Dental Materials, Saunders, St. Louis, MO, USA, 12 edition, 2012.

[10] D. C. Jagger, A. Harrison, R. G. Jagger, and P. Milward, "The effect of the addition of poly(methyl methacrylate) fibres on some properties of high strength heat-cured acrylic resin denture base material," Journal of Oral Rehabilitation, vol. 30, no. 3, pp. 231-235, 2003.

[11] P. K. Vallittu, H. Vojtkova, and V. P. Lassila, "Impact strength of denture polymethyl methacrylate reinforced with continuous glass fibers or metal wire," Acta Odontologica Scandinavica, vol. 53, no. 6, pp. 392-396, 1995.

[12] D. L. Dixon and L. C. Breeding, "The transverse strengths of three denture base resins reinforced with polyethylene fibers," The Journal of Prosthetic Dentistry, vol. 67, no. 3, pp. 417-419, 1992.

[13] L. M. Fais, L. A. P. Pinelli, R. H. B. T. Silva, J. C. M. Segalla, and C. C. Marcelo, "Efeito da ciclagem mecânica sobre a resistência flexural de resinas acrílicas reforçadas por fibras de vidro," $R F O$ UPF, vol. 11, pp. 21-25, 2006.

[14] J. B. Woelfel, “Processing complete dentures," Dental Clinics of North America, vol. 21, pp. 329-338, 1977.

[15] International Standardization Organization, "Dentistry-Base polymers-Part 1: Denture base polymers. ISO 20795-1, Genéve," 2013.

[16] J. John, S. A. Gangadhar, and I. Shah, "Flexural strength of heatpolymerized polymethyl methacrylate denture resin reinforced with glass, aramid, or nylon fibers," Journal of Prosthetic Dentistry, vol. 86, no. 4, pp. 424-427, 2001.

[17] I. Kostoulas, V. T. Kavoura, M. J. Frangou, and G. L. Polyzois, "Fracture force, deflection, and toughness of acrylic denture repairs involving glass fiber reinforcement," Journal of Prosthodontics, vol. 17, no. 4, pp. 257-261, 2008.

[18] D. C. Jagger, A. Harrison, and K. D. Jandt, "The reinforcement of dentures," Journal of Oral Rehabilitation, vol. 26, no. 3, pp. 185-194, 1999.

[19] A. D. Bona, K. J. Anusavice, and P. H. DeHoff, "Weibull analysis and flexural strength of hot-pressed core and veneered ceramic structures," Dental Materials, vol. 19, no. 7, pp. 662-669, 2003.

[20] J. M. D. S. N. Reis, C. E. Vergani, A. C. Pavarina, E. T. Giampaolo, and A. L. Machado, "Effect of relining, water storage and cyclic loading on the flexural strength of a denture base acrylic resin," Journal of Dentistry, vol. 34, no. 7, pp. 420-426, 2006.

[21] R. S. Seo, H. Murata, G. Hong, C. E. Vergani, and T. Hamada, "Influence of thermal and mechanical stresses on the strength of intact and relined denture bases," Journal of Prosthetic Dentistry, vol. 96, no. 1, pp. 59-67, 2006.

[22] G. S. Chandu, P. Asnani, S. Gupta, and M. F. Khan, "Comparative evaluation of effect of water absorption on the surface properties of heat cure acrylic: an in vitro study," Journal of International Oral Health, vol. 7, pp. 63-68, 2015. 

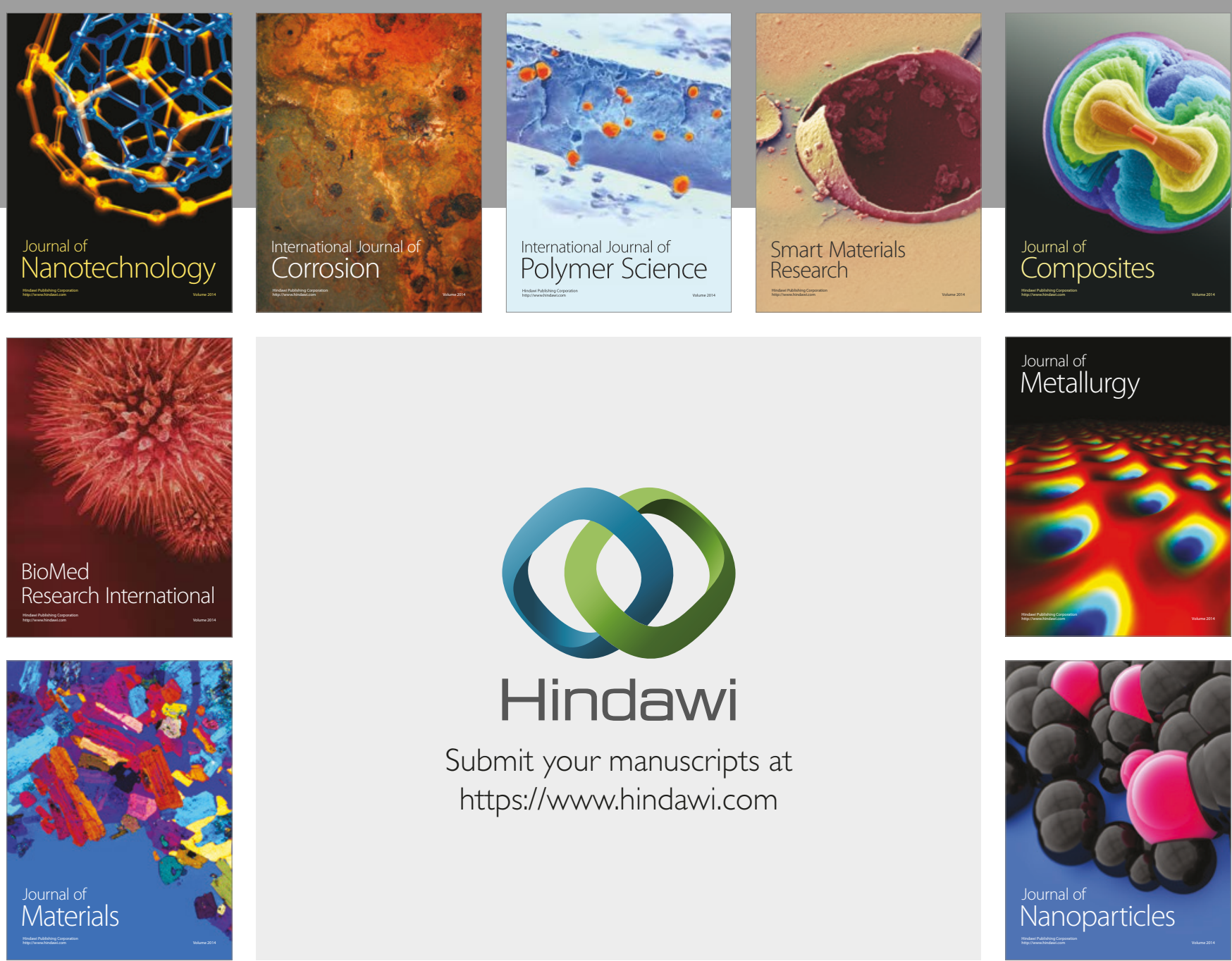

\section{Hindawi}

Submit your manuscripts at

https://www.hindawi.com
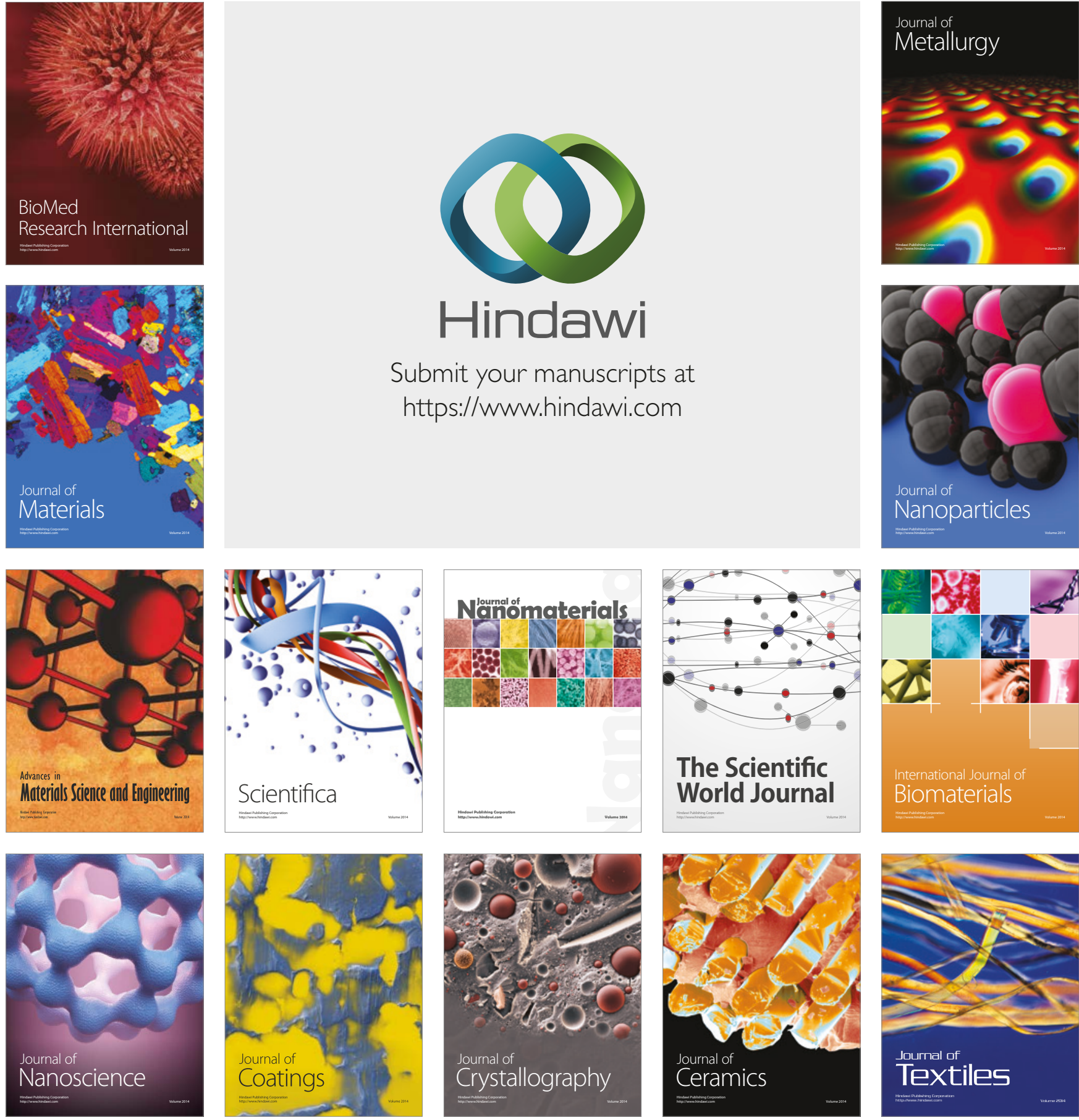

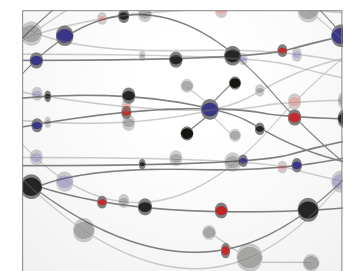

The Scientific World Journal
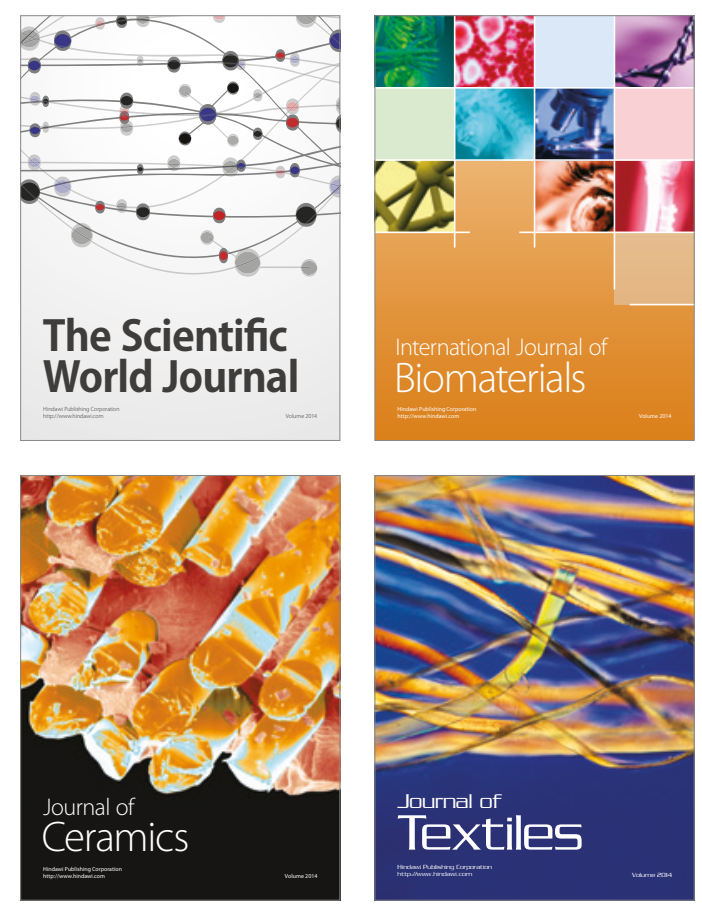